\title{
Antidiabetic activity evaluation of Onobrychis species on alloxan- induced diabetic mice
}

\author{
Hanefi Ozbek , Ozlem Bahadir Acikara², Burcin Ergene Oz$^{2}$, Serkan Ozbilgin², Neriman Ipek \\ Kirmizi $^{3^{*}}$, Bade Cevriye Ozrenk ${ }^{3}$, Mehmet Tekin ${ }^{4}$, Gulcin Saltan²
}

\begin{abstract}
${ }^{1}$ Ístanbul Medipol University, Faculty of Medicine, Department of Pharmacology, Istanbul, Turkey, ${ }^{2}$ Ankara University, Faculty of Pharmacy, Department of Pharmacognosy, Ankara, Turkey, ${ }^{3}$ Istanbul Medipol University, IMU Vocational School, Department of Occupational Health and Safety, Istanbul, Turkey, ${ }^{4}$ Trakya University, Faculty of Pharmacy, Department of Pharmaceutical Botany, Sivas, Turkey
\end{abstract}

\begin{abstract}
In the current study, four Onobrychis species, O. albiflora Hub.-Mor., O. argyrea Boiss. subsp. argyrea Boiss., O. galegifolia Boiss., and O. tournefortii (Willd.) Desv. were collected from Anatolia to be evaluated for their antidiabetic activities. Methanol water extracts of the aerial parts were used for experiments. An alloxan-induced diabetic mice test model was used. Phytochemical analysis of the tested extracts was investigated using the HPLC method. The highest activity was observed with treatment of $O$. albiflora aerial part extract. Significant decrements were detected in the blood glucose levels as follows: $180.83 \pm 47.48$ and $252.83 \pm 50.47 \mathrm{mg} / \mathrm{dL}$ at $100 \mathrm{mg} / \mathrm{kg}$ and $200 \mathrm{mg} / \mathrm{kg}$ doses of O. albiflora, respectively, when compared to the isotonic saline solution control group, eliciting a blood glucose level of $494.20 \pm 27.32$. Among the tested standard compounds, rutin and isoquercetin were detected in the examined species. The highest amount of rutin $(1.1981 \pm 0.0017 \%)$ and isoquercetin $(0.7318 \pm 0.0197 \%)$ were found in $O$. albiflora and $O$. argyrea subsp. argyrea, respectively. Antidiabetic activities of the tested Onobrychis species seem to indicate a possible correlation with their rutin and isoquercetin contents. Therefore, rutin and isoquercetin may be the antidiabetic compounds that contribute to the antidiabetic activity of the tested Onobrychis species.
\end{abstract}

Keywords: Onobrychis. Antidiabetic activity. Alloxan. Rutin. Isoquercetin. Phytochemical analysis.

\section{INTRODUCTION}

Onobrychis Miller belongs to the Fabaceae family and is widely distributed in Southwest Asia, Mediterranean countries, and temperate regions of Europe; with around 170 species (Karamian, Asadbegy 2016). Onobrychis viciifolia Scop., known as sainfoin, is used as fodder legume in many countries and has many beneficial effects for ruminants, including providing high protein and energy value, exhibiting antihelmintic activity in cattle and sheep with preventive activities against bloat; which are attributed to the tannin content of the plant (Regos, Urbanella, Treutter, 2009). From a chemical point of view, no sufficient studies have been conducted on the Onobrychis species. Onobrychis viciifolia, the best known species of this genus, contains

\footnotetext{
*Correspondence: N. I. Kirmizi. Istanbul Medipol University, IMU Vocational School, Department of Occupational Health and Safety, Istanbul, Turkey. E-mail: nikirmizi@medipol.edu.tr
}

proanthocyanidin polymers (Koupai-Abyazani et al., 1993), cinnamic acid derivatives, flavonoid glycosides (Lu et al., 2000), isoflavonoids, and acylated flavonoids (Veitch et al., 2011). Biological activity studies also revealed that Onobrychis species have not been yet investigated properly. Antibacterial activity and moderate antitumor activity by aerial parts of $O$. oxyodonta Boiss. have also been reported after the experiments using the potato disc method (Usta, Yildirim, Turker, 2014). $O$. armena Boiss \& Huet flower and roots were reported to display antioxidant activity as well as antimicrobial activity against some bacteria, fungus, and fish pathogens, but no cytotoxic activity was reported on kidney fibroblast (BHK 21) cells (Karakoca et al., 2015). The antioxidant activity of $O$. hyparygrea Boiss. in different test models was examined and moderate antioxidant properties were determined in ethyl acetate, methanol, and water extracts in all test systems when compared to trolox and EDTA as positive controls. Methanol and aqueous extracts of $O$. 
hyparygrea also inhibited $\alpha$-glucosidase with $3.89 \pm 0.097$ and $5.86 \pm 0.050 \mathrm{mg} / \mathrm{mL} \mathrm{IC}_{50}$ values, respectively (Zengin et al., 2015). O. viciifolia, O. sosnovskyi Grossh, and $O$. melanotricha Boiss. aerial parts were reported to have strong antioxidant activities in DPPH radical scavenging, metal chelating, and $\beta$-carotene bleaching methods (Karamian, Asadbegy, 2016).

In the current study, the aerial parts of four different Onobrychis species namely, O. albiflora Hub.-Mor., O. argyrea Boiss. subsp. argyrea Boiss., O. galegifolia Boiss., and O. tournefortii (Willd.) Desv. were evaluated for their potential antidiabetic activities in alloxan-induced diabetic mice. Furthermore, the phytochemical content of the aerial parts was analyzed using the HPLC method.

\section{MATERIAL AND METHODS}

\section{Plant material}

Onobrychis species were collected from different regions of Anatolia (Table I). Taxonomic identification of the plants was confirmed by Assistant Professor Mehmet Tekin (Cumhuriyet University, Faculty of Pharmacy, Department of Pharmaceutical Botany). Voucher specimens were kept in the Herbarium of Cumhuriyet University, Faculty of Science (CUFH).

\section{Extraction of plant materials for biological activity tests}

Dried and powdered aerial parts of each plant $(30 \mathrm{~g})$ were extracted with a $300 \mathrm{~mL}$ methanol water solution $(80: 20)$ at room temperature during $8 \mathrm{~h}$ for 3 days by continuous stirring. Each extract was filtered and concentrated to dryness under reduced pressure and low temperature $\left(40-50^{\circ} \mathrm{C}\right)$ on a rotary evaporator to yield crude extracts.

TABLE I - List of Onobrychis species collected for the study

\section{HPLC analysis}

HPLC analyses were carried out using an Agilent LC 1200 model chromatograph (Agilent Technologies, California, USA). The diode array detector (DAD) was set at wavelengths of $210 \mathrm{~nm}, 254 \mathrm{~nm}$ and $330 \mathrm{~nm}$, and peak areas were integrated automatically using Agilent computer software. The chromatograms were plotted and processed using the above mentioned software. Separation was carried out using an ACE 5 C18 $(250 \mathrm{~mm} \times 4.6 \mathrm{~mm}$; $5 \mu \mathrm{m})$ column. The mobile phase was composed of $0.2 \%$ phosphoric acid in water (A), acetonitrile (B), and in gradient elution: initially $0 \mathrm{~min}, \mathrm{~A}-\mathrm{B}(90: 10$, v/v); then $0-10 \mathrm{~min}$, linear change from $\mathrm{A}-\mathrm{B}(90: 10, \mathrm{v} / \mathrm{v})$ to $\mathrm{A}-\mathrm{B}$ (80:20); then 10-20 min, linear change to $\mathrm{A}-\mathrm{B}(80: 20)$; then 20-35 min, linear change to A-B (70:30); then 35-45 min, linear change to A-B (30:70); then 45-50 min, linear change to $\mathrm{A}-\mathrm{B}(0: 100)$, and $50-55 \mathrm{~min}$, isocratic elution was from $\mathrm{A}-\mathrm{B}(0: 100)$. The flow rate was $0.5 \mathrm{~mL} / \mathrm{min}$ and column temperature was maintained at $20^{\circ} \mathrm{C}$. The sample injection volume was $10 \mu \mathrm{L}$.

\section{Extraction procedure, preparation of standard and sample solutions}

Aerial parts of the four different Onobrychis species were used in this experiment. A methanol water solution (80:20) was used for the extraction of plant samples. For HPLC analysis, $10 \mathrm{mg}$ of methanol water extracts of four species were weighed in $10 \mathrm{~mL}$ volumetric flasks, dissolved in methanol water solutions and adjusted to the final volume separately. Each extract was filtered through a $0.45 \mu \mathrm{m}$ membrane filter after adjusting to a final volume of $10 \mathrm{~mL}$ with the same solvent. Triplicate $10 \mu \mathrm{L}$ injections were performed for the plant samples.

Standard stock solutions were prepared as follows: $0.1 \mathrm{mg} / \mathrm{mL}$ for caffeic acid, ferulic acid, luteolin-7-

\begin{tabular}{lcc}
\hline Plant Species & Location & $\begin{array}{c}\text { Collector and } \\
\text { herbarium number }\end{array}$ \\
\hline O. albiflora & Sivas: Sincan to Kangal, 3. km roadside $1220 \mathrm{~m}$, & M. Tekin, 1291 \\
& $39^{\circ} 28^{\prime} 01,9^{\prime \prime} \mathrm{N} ; 37^{\circ} 50^{\prime} 34,5^{\prime \prime} \mathrm{E}$ & \\
O. argyrea subsp. argyrea & Sivas: Zara - Divrigi road, $55 \mathrm{~km}$ from Divrigi $1691 \mathrm{~m}$, & M. Tekin, 1293 \\
O. galegifolia & $39^{\circ} 36^{\prime} 58,1^{\prime \prime} \mathrm{N} ; 37^{\circ} 44^{\prime} 28,4^{\prime \prime} \mathrm{E}$ & \\
& Sivas: Divrigi to Sincan, 2-3 km from Sincan, roadside, $1312 \mathrm{~m}$, & M. Tekin, 1294 \\
O. tournefortii & $39^{\circ} 30^{\prime} 21,7^{\prime \prime} \mathrm{N} ; 37^{\circ} 49^{\prime} 45,4^{\prime \prime} \mathrm{E}$ & \\
& Sivas: Sivas to Hafik, Emre village vicinity, $1317 \mathrm{~m}$, & M. Tekin 1290 \\
\hline
\end{tabular}


glucoside, hyperoside, isoquercetin, rutin, orientin, myricetin, and apigenin. All compounds were weighed in a $10 \mathrm{~mL}$ volumetric flask, dissolved in a methanol water solution (80:20) and adjusted to the final volume separately. Different concentration levels (between 0.0005 $\mathrm{mg} / \mathrm{mL}-0.05 \mathrm{mg} / \mathrm{mL}$ ) were prepared by diluting the stock solution. Triplicate $10 \mu \mathrm{L}$ injections were performed for each standard solution. The peak area of each solution was plotted against the concentration to obtain the calibration curves.

\section{Validation procedure - Limit of detection and quantification}

Limit of detection (LOD) and limit of quantification $(\mathrm{LOQ})$ were established at signal to noise $(\mathrm{S} / \mathrm{N})$ ratios of 3 and 10, respectively. LOD and LOQ concentrations were experimentally verified by 9 injections of standard compounds.

\section{Animals}

The study protocol [30/09/2015-69] was approved by the Ethics Committee of Istanbul Medipol University. Balb/C strain mice [22-30 g] obtained from Istanbul Medipol University Regenerative and Restorative Medical Center (REMER), were used for this experiment. The animals were housed in standard cages $[48 \mathrm{~cm} \times 35 \mathrm{~cm}$ $\times 22 \mathrm{~cm}]$ at room temperature $\left[22 \pm 2{ }^{\circ} \mathrm{C}\right]$, with artificial light from 7.00 am to $7.00 \mathrm{pm}$, and provided with pelleted food and water ad libitum.

\section{Chemicals}

Alloxan was obtained from Sigma [SteinheimGermany]. Onobrychis extracts were prepared using water $[\mathrm{w} / \mathrm{v}]$ before being given to the mice.

\section{Antidiabetic activity assay}

An alloxan-induced test model was used to evaluate antidiabetic activity (Kumar et al., 2008; Tripathi, Verma, 2014; Ozbek et al., 2017). Mice were kept without food for 18 hours before the alloxan treatment. Alloxan was applied in an isotonic saline solution by i.p. [intraperitoneal] administration $[150 \mathrm{mg} / \mathrm{kg}]$ three times over a 48-hour period. Mice were kept without food following the last alloxan treatment, and blood glucose levels were measured. Mice with blood glucose levels of $200 \mathrm{mg} / \mathrm{dL}$ and higher were subjected to further studies as diabetic animals. Diabetic mice were divided into nine groups in order to determine the antidiabetic activities of Onobrychis aerial part extracts (all extracts were dissolved in an isotonic saline solution). Animals were assigned into following groups $(n=6)$ : Group 1, the control group, received isotonic saline solution [ISS] $0.1 \mathrm{~mL}$; Group 2 and Group 3 received $O$. tournefortii extract $100 \mathrm{mg} / \mathrm{kg}$ and $200 \mathrm{mg} / \mathrm{kg}$ i.p., respectively; Group 4 and Group 5 received $O$. argyrea subsp. argyrea extract $100 \mathrm{mg} / \mathrm{kg}$ and $200 \mathrm{mg} / \mathrm{kg}$ i.p., respectively; Group 6 and Group 7 received $O$. galegifolia extract $100 \mathrm{mg} / \mathrm{kg}$ and $200 \mathrm{mg} /$ kg i.p., respectively; and finally Group 8 and Group 9 received O. albiflora extract $100 \mathrm{mg} / \mathrm{kg}$ and $200 \mathrm{mg} / \mathrm{kg}$ i.p, respectively.

Following the administration of the tested extracts, blood samples collected from the tail in the $1^{\text {st }}, 2^{\text {nd }}$ and $4^{\text {th }}$ hours were measured for their glucose concentrations using an Accu-Check ${ }^{\circledR}$ sugar strip according to the glucose-oxidase-peroxidase method.

\section{Statistical analyses}

Statistical analysis was carried out using SPSS 18.0 software. The results were reported as mean \pm SEM [standard error of mean]. A one-way analysis of variance [post-hoc Tukey's HSD, Dunnett-t test] was used for statistical analyses. Probability levels of less than 0.05 $[\mathrm{P}<0.05]$ were considered as significant.

\section{RESULTS}

\section{HPLC analysis}

O. albiflora, O. argyrea subsp. argyrea, $O$. galegifolia, and $O$. tournefortii were analyzed for their phenolic contents using the HPLC method. The HPLC method was developed by comparing the chromatographic profile and data obtained from the standards and samples, considering the following parameters: retention time, analyzing time for samples, separation, peak shapes, and maximum UV absorption of the standards. Figure 1 displays the chromatogram of the aerial part extract of $O$. albiflora, and Figure 2 and Figure 3 show the standard compounds. Peaks were identified by comparison of the retention times and UV absorption spectra with the acquired standards.

For the quantification of the phenolic compounds, standard stock solutions were prepared as described in the experimental section, and diluted to six different concentrations to establish the calibration curves. All calibration curves showed good linearity responses with high correlation coefficients. The contents of the 


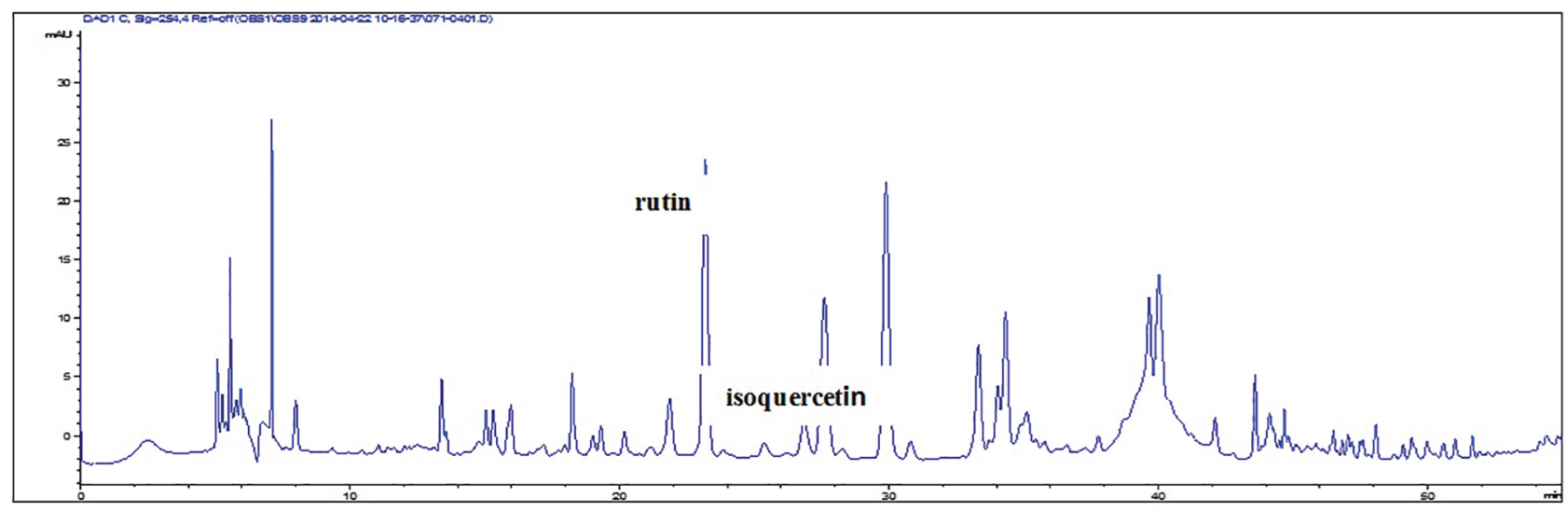

FIGURE 1 - HPLC chromatogram of O. albiflora.

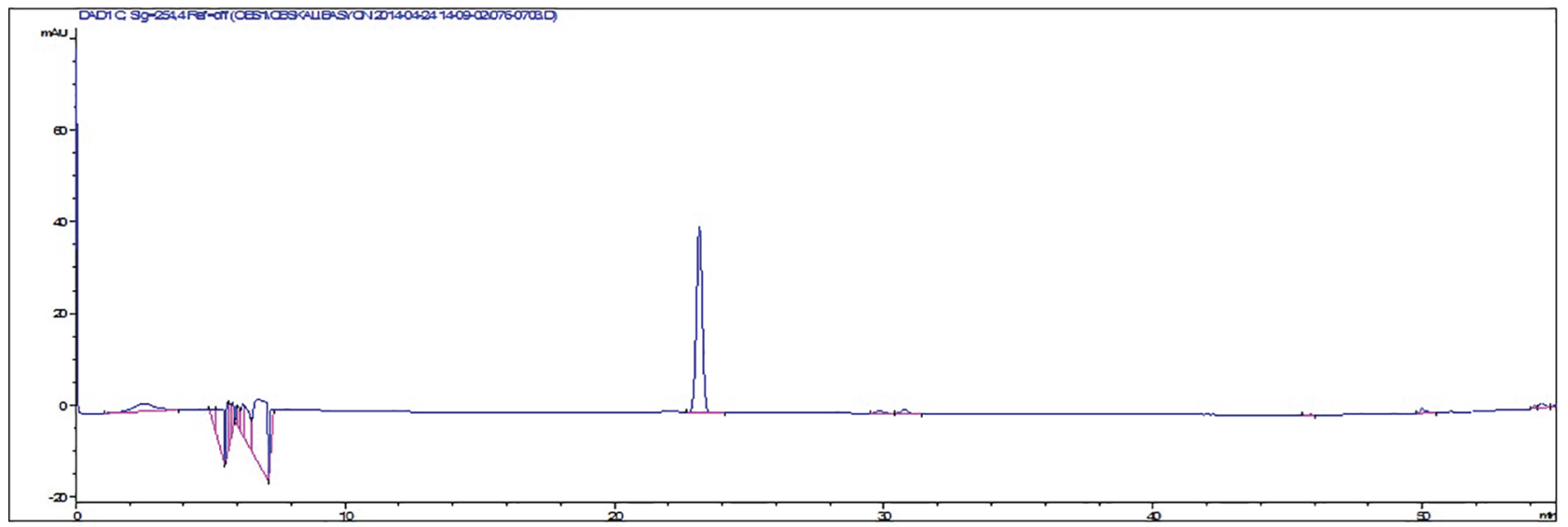

FIGURE 2 - HPLC chromatogram of rutin.

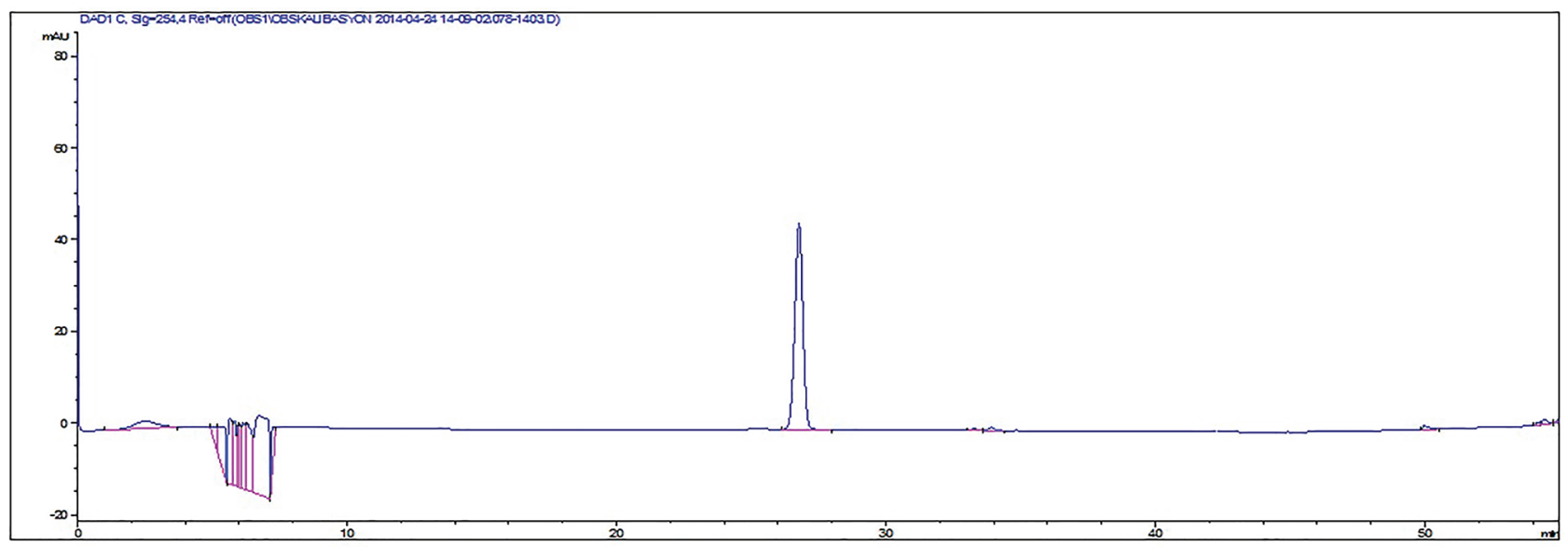

FIGURE 3 - HPLC chromatogram of isoquercetin

extracts are shown in Table II and the results are given as percentages (\%) in plant material. Among the tested compounds, rutin was identified in all Onobrychis species tested, and the highest concentration was detected in aerial parts of $O$. albiflora $(1.1981 \pm 0.0017 \%)$. Isoquercetin was also found in all Onobrychis species, except $O$. galegifolia.
O. argyrea subsp. argyrea contained the highest percentage of isoquercetin $(0.7318 \pm 0.0197 \%)$, (Table II).

LOD and LOQ concentrations were determined as 0.103 and $0.344 \mu \mathrm{g} / \mathrm{mL}$ for rutin, whereas these were 0.0944 and $0.315 \mu \mathrm{g} / \mathrm{mL}$ for isoquercetin, respectively. 
TABLE II - Rutin and isoquercetin content of Onobrychis species

\begin{tabular}{lcc}
\hline Plant Species & Rutin (\%) & Isoquercetin (\%) \\
\hline O. albiflora & $1.1981 \pm 0.0017$ & $0.1288 \pm 0.0003$ \\
O. argyrea subsp. argyrea & $0.3719 \pm 0.0012$ & $0.7318 \pm 0.0197$ \\
O. galegifolia & $0.1462 \pm 0.0003$ & - \\
O. tournefortii & $0.2135 \pm 0.0004$ & $0.4077 \pm 0.0000$ \\
\hline
\end{tabular}

TABLE III - Blood sugar levels of alloxan-induced diabetic mice

\begin{tabular}{|c|c|c|c|c|}
\hline \multirow[t]{3}{*}{ Groups } & \multicolumn{4}{|c|}{ Blood sugar levels (mg/dL) } \\
\hline & \multirow{2}{*}{$\begin{array}{c}\text { Before Onobrychis } \\
\text { treatment }\end{array}$} & \multicolumn{3}{|c|}{ After Onobrychis treatment } \\
\hline & & $1 \mathrm{~h}$ & $2 \mathrm{~h}$ & $4 \mathrm{~h}$ \\
\hline Control (ISS) & $470,60 \pm 23,62$ & $471,00 \pm 13,78$ & $493,80 \pm 15,55$ & $494,20 \pm 27,32$ \\
\hline OT $100 \mathrm{mg} / \mathrm{kg}$ & $390,50 \pm 36,55$ & $322,33 \pm 30,25$ & $294,83 \pm 32,71^{*}$ & $333,50 \pm 43,67$ \\
\hline OT $200 \mathrm{mg} / \mathrm{kg}$ & $374,00 \pm 34,22$ & $364,17 \pm 26,24$ & $352,17 \pm 43,85$ & $268,50 \pm 41,61^{*}$ \\
\hline OAA $100 \mathrm{mg} / \mathrm{kg}$ & $378,67 \pm 52,78$ & $399,00 \pm 27,51$ & $365,67 \pm 45,75$ & $286,33 \pm 44,58^{*}$ \\
\hline OAA $200 \mathrm{mg} / \mathrm{kg}$ & $352,50 \pm 50,06$ & $415,83 \pm 40,47$ & $374,00 \pm 47,23$ & $332,33 \pm 52,78$ \\
\hline OG $100 \mathrm{mg} / \mathrm{kg}$ & $357,17 \pm 49,07$ & $358,50 \pm 61,88$ & $338,83 \pm 55,95$ & $340,83 \pm 40,93$ \\
\hline OG $200 \mathrm{mg} / \mathrm{kg}$ & $430,33 \pm 16,84$ & $442,50 \pm 17,63$ & $427,33 \pm 20,82$ & $373,33 \pm 34,07$ \\
\hline OA100 mg/kg & $374,17 \pm 27,79$ & $292,83 \pm 56,01$ & $235,17 \pm 45,85^{*}$ & $180,83 \pm 47,48^{*}$ \\
\hline OA $200 \mathrm{mg} / \mathrm{kg}$ & $419,50 \pm 20,67$ & $375,16 \pm 14,48$ & $349,43 \pm 60,90$ & $252,83 \pm 50,47^{*}$ \\
\hline F/p-value & $1,000 / 0,450$ & $1,838 / 0,095$ & $2,613 / 0,020$ & $3,744 / 0,002$ \\
\hline
\end{tabular}

OA: O. albiflora, OAA: O. argyrea subsp. argyrea, OG: O. galegifolia, OT: O. tournefortii

\section{Antidiabetic activity}

Aerial part extracts of $O$. albiflora, O. argyrea subsp. argyrea, $O$. galegifolia, and $O$. tournefortii were tested for their potential antidiabetic activities using alloxan-induced diabetic animals in current study. Blood glucose levels were measured at four different times; before Onobrychis extract treatment and after 1, 2 and 4 hours of treatment. All measured levels of blood glucose are presented in Table III. O. tournefortii and O. albiflora were associated with significantly decreased blood glucose levels at $100 \mathrm{mg} / \mathrm{kg}$ dose after 2 hours of treatment when compared to isotonic saline group. O. tournefortii $200 \mathrm{mg} / \mathrm{kg}, O$. argyrea subsp. argyrea $100 \mathrm{mg} / \mathrm{kg}$, and O. albiflora $100 \mathrm{mg} / \mathrm{kg}$ and 200 $\mathrm{mg} / \mathrm{kg}$ caused notable decrease in blood glucose level after 4 hours of treatment as shown in Table III. However, $O$. albiflora aerial part extract displayed the highest activity at $100 \mathrm{mg} /$ dose and after 4 hours of treatment.

\section{DISCUSSION}

Our study showed that $O$. albiflora treatment resulted in the highest antidiabetic activity in alloxan- induced diabetic animals at $100 \mathrm{mg} / \mathrm{kg}$ dose. The highest level of activity was observed after 4 hours of treatment. However, increasing the dosage to $200 \mathrm{mg} / \mathrm{kg}$ did not reduce blood sugar levels in animals even after 4 hours of the $O$. albiflora treatment. O. tournefortii and O. argyrea subsp. argyrea were determined to be effective at 200 $\mathrm{mg} / \mathrm{kg}$ and $100 \mathrm{mg} / \mathrm{kg}$ doses, respectively, after 4 hours of treatment. Both extracts lead to slight reductions in blood glucose levels when compared to $O$. albiflora. $O$. galegifolia did not significantly reduce elevated blood glucose levels, but displayed a tendency to lower the blood glucose at 1,2 and 4 hours when compared with the control group. These results demonstrated that treatment with $O$. albiflora could significantly improve blood glucose levels in alloxan-induced diabetic animals.

We used the alloxan-induced diabetic model, a well-known method of evaluating especially the type I DM. Alloxan selectively destroys insulin-producing beta cells found in the pancreas. A sudden increase in insulin secretion induced by alloxan treatment, in the presence or absence of glucose, is associated with a complete suppression of beta islet response to glucose, even when high glucose concentrations are used (Rohilla, Ali, 2012; 
Tripathi, Verma, 2014). Alloxan inhibits glucose-induced insulin secretion by inhibiting the enzyme glucokinase, a glucose sensor in beta cells, by reacting with two - $\mathrm{SH}$ groups in the sugar binding site. Alloxan and dialuric acid, a reduction product of alloxan, induces a redox cycle resulting in the formation of reactive oxygen species (ROS) and superoxide radicals. Ferric ions from ferritin are released by superoxide radicals and transformed to ferrous and ferric ions. Additionally, superoxide radicals undergo dismutation to hydrogen peroxide in the presence of superoxide dismutase, and highly active hydroxyl radicals are formed. The destruction of beta cells occurs rapidly due to ROS with simultaneous excessive increases in cytosolic calcium concentration (Rohilla, Ali, 2012; Tripathi, Verma, 2014). Alloxan-induced toxicity can be prevented by enzymatic antioxidants such as catalase and dismutase, as well as non-enzymatic hydroxyl radical scavengers (Etuk, 2010).

Experimental and clinical evidence has revealed that ROS are elevated in both types of diabetes, and play an important role in the development and progression of DM. In normal healthy cells, the presence of the protective activity of antioxidant enzymes and the nonenzymatic antioxidant levels of ROS can be controlled. However, excessive cellular levels of ROS induced by hyperglycemia in diabetics cause major complications (Matough et al., 2012). Multiple factors induce increased oxidative stress in diabetics. ROS generation can be elevated directly by hyperglycemia. Glucose autoxidation is one of the main factors among these resulting ${ }^{\circ} \mathrm{OH}$ radicals. Moreover, glucose reacts with proteins which promote the formation of advanced glycation end-products (Johansen et al., 2005; Jebur, Mokhamer, El-Demerdash, 2016). Additionally, increased production of ${ }^{\circ} \mathrm{O}_{2}^{-}$occurs in hyperglycemic subjects due to the enhanced metabolism of glucose. NOS, NAD(P)H oxidase, and xanthine oxidase are the enzymatic sources of reactive species in diabetics. ${ }^{\circ} \mathrm{O}_{2}^{-}$production is increased by enzymatic sources and predominantly mediated by $\mathrm{NAD}(\mathrm{P}) \mathrm{H}$ oxidase. Furthermore, a mitochondrial respiratory chain precipitates the hyperglycemic induced generation of ${ }^{\circ} \mathrm{O}_{2}{ }^{-}$ at the mitochondrial level in diabetics (Johansen et al., 2005). The long-term complications in diabetic patients include damage, dysfunction, and failure of different organs; resulting in retinopathy, nephropathy, neuropathy, atherosclerosis, coronary artery diseases, cerebrovascular, and peripheral vascular diseases (Matough et al., 2012). Oxidative stress caused by hyperglycemia induces free radicals to play an important role in the development and progression of diabetes mellitus (Johansen et al., 2005; Matough et al., 2012). Treatment with antioxidants could be an effective strategy for improving diabetic complications (Johansen et al., 2005). Naturally occurring antioxidants such as vitamin $\mathrm{C}, \mathrm{E}$ and $\alpha$-lipoic acid treatments were reported to reduce the oxidative stress experimentally in diabetic animals and clinically in human (Johansen et al., 2005; Jebur et al., 2016). For this reason, recently there has been an increasing interest in natural antioxidants derived from plant materials. Natural antioxidants occur in all parts of plants as phytochemicals such as monoterpenes, diterpenes, triterpenes, and phenolic compounds, flavonoids, coumarins, lignans, phenylpropanoids, and tannins (Jebur, Mokhamer, ElDemerdash, 2016). It has been reported that species of Onobrychis also have important antioxidant activities. $O$. armena Boiss \& Huet flowers and roots have antioxidant capacities as shown by the phosphomolybdenum method, cupric ion reducing antioxidant capacity, DPPH radical scavenging activity, and ferric ion reducing capacity (Karakoca et al., 2015). Total antioxidant capacity, scavenging activities against DPPH and ABTS radicals, metal chelating activity of ferrous ions, $\beta$-carotene/ linoleic acid bleaching activity, ferric reducing antioxidant power and cupric ion reducing antioxidant capacity were measured to determine the antioxidant activity of $O$. hyparygrea Boiss. Moderate antioxidant capacities were observed in ethyl acetate, methanol, and water extracts in all test systems when compared to trolox and EDTA as positive controls (Zengin et al., 2015). O. viciifolia, $O$. sosnovskyi Grossh and O. melanotricha Boiss. aerial parts were also reported to have strong antioxidant activities in DPPH radical scavenging, metal chelating, and $\beta$-carotene bleaching methods (Karamian and Asadbegy 2016). The total antioxidant capacity of $O$. altissima Grossh was determined to be an ABTS radical scavenger, and the plant's ability to reduce glutathione levels was identified (Erbil et al., 2015). The current study did not report on the biological activities of $O$. albiflora, O. argyrea subsp. argyrea, O. galegifolia, and $O$. tournefortii in terms of their antidiabetic activities. However, previous studies of the Onobrychis genus could be used to suggest that potential antioxidant activities may contribute to their antidiabetic effects.

In order to clarify the active compound(s) of the tested Onobrychis species, HPLC analysis was performed by using some standard compounds. Among the tested phenolic compounds, rutin and isoquercetin were determined. The presence of rutin was detected in all tested species while isoquercetin was detected in $O$. albiflora, $O$. argyrea subsp. argyrea and $O$. tournefortii. The highest content of rutin and isoquercetin was found in $O$. albiflora and O. argyrea subsp. argyrea, respectively. 
O. albiflora displayed the highest antidiabetic activity while $O$. galegifolia exhibited non-significant activity due to having the lowest rutin content. Antidiabetic activities of the tested Onobrychis species seem to be correlated with rutin content. In fact, antidiabetic activities of rutin and isoquercetin were reported previously. Rutin treatment was associated with decreased levels of plasma glucose, glycosylated hemoglobin, thiobarbituric acid reactive substances, and lipid hydroperoxides, and elevated levels of insulin, C-peptide, and non-enzymatic antioxidants such as glutathione, vitamin $\mathrm{C}, \mathrm{E}$, and ceruloplasmin in streptozotocin-induced diabetic rats. On the other hand, in normal rats, no parameters were altered by rutin treatment. It was suggested that rutin acted as a free radical scavenger and inhibited lipid peroxidation resulting in the prevention of oxidative stress and the protection of beta cells (Kamalakkannan, Stanley, Prince, 2006). Rutin significantly lowered plasma glucose levels and increased insulin levels. Besides, the restoration of glycogen content and activities of carbohydrate metabolic enzymes was observed in diabetic mice treated with a 100 $\mathrm{mg} / \mathrm{kg}$ dose. Glucose uptake by rutin treatment has been shown in rat soleus muscle through PI3K, a typical protein kinase $\mathrm{C}$ and mitogen-activated protein kinase pathways (Vinayagam, Xu, 2015). Jadhav and Puchchakayala reported that rutin reduced blood glucose levels after $2 \mathrm{~h}$ and $4 \mathrm{~h}$ in streptozotocin/nicotinamide-induced diabetic rats. The mechanism of rutin was thought to be increased peripheral utilization of glucose and inhibition of glucose transport (Jadhav, Puchchakayala, 2012). It was also reported that in diabetic rats induced by high fat diet + streptozotocin, rutin treatment $(50 \mathrm{mg} / \mathrm{kg}$ and $100 \mathrm{mg} /$ $\mathrm{kg}$ ) for three weeks improved the metabolic status of rats. Plasma glucose levels and glycosylated hemoglobin, as well as proinflammatory cytokines (IL-6 and TNF-alpha) were reduced. Liver antioxidant status and serum lipid profile were also improved (Niture, Ansari, Naik, 2014). Furthermore, protective and ameliorative effects of rutin in myocardial dysfunction, oxidative stress, apoptosis, and inflammation were observed in the hearts of diabetic rats (Vinayagam, Xu, 2015). Isoquercetin was also identified as the compound responsible for the antidiabetic activity of Vaccinium vitis idaea. Isoquercetin, as well as its aglycone quercetin, stimulated the AMPK pathway at 25$100 \mathrm{mM}$ concentrations. Both isoquercetin and quercetin compounds enhanced glucose uptake by $38-59 \%$ and $37 \%$, respectively. However, inhibition of ATP synthase in isolated mitochondria was achieved only by quercetin at 25 and $100 \mathrm{mM}$ (34\% and 79\%), respectively (Eid et al., 2010). Furthermore, hepatic glucose-6-phosphatase was inhibited by isoquercetin in vitro(Hung et al., 2012).
The short period of time used for the study procedure could be regarded as a limitation of current study. Therefore, further studies should be performed to observe for the potential long-term antidiabetic effects of the Onobrychis species.

In conclusion, $O$. albiflora that contains rutin in relatively high amounts was determined to be most effective species for alloxan-induced diabetic mice test models. This was followed by $O$. tournefortii at $200 \mathrm{mg} / \mathrm{kg}$ dose, and $O$. argyrea subsp argyrea at $100 \mathrm{mg} / \mathrm{kg}$ dose. $O$. galegifolia, which exhibited the least activity, contained no isoquercetin and contained rutin in very low levels when compared to other species. It could be suggested that rutin could be the main compound responsible for antidiabetic activities of the tested Onobrychis species. Additionally, isoquercetin, which has been proven to be an antidiabetic compound in earlier studies, could contribute to the Onobrychis' antidiabetic activities. Nevertheless, further studies are warranted to reveal responsible compounds and to identify their mechanisms.

\section{REFERENCES}

Eid HM, Martineau LC, Saleem A, Muhammad A. Stimulation of AMP-activated protein kinase and enhancement of basal glucose uptake in muscle cells by quercetin and quercetin glycosides, active principles of the antidiabetic medicinal plant Vaccinium vitis-idaea. Mol Nutr Res. 2010;54(7):991-1003.

Erbil N, Duzguner V, Durmuskahya C, Alan Y. Antimicrobial and Antioxidant Effects of Some Turkish Fodder Plants Belongs to Fabaceae Family (Vicia villosa, Trifolium ochroleucum and Onobrychis altissima). Orient J Chem. 2015;31(3):53-8.

Etuk EU. Animals models for studying diabetes mellitus. Agric Biol J N Am. 2010;1(2):130-4.

Hung H, Qian K, Morris-Natschke SL, Hsu C, Lee K. Recent discovery of plant-derived anti-diabetic natural products. Nat Prod Rep. 2012;29(5):580-606.

Jadhav R, Puchchakayala G. Hypoglycemic and antidiabetic activity of flavonoids: boswellic acid, ellagic acid, quercetin, rutin on streptozotocin-nicotinamide induced type 2 diabetic rats. Int J Pharm Pharm Sci. 2012;4(2):251-7.

Jebur AB, Mokhamer MH, El-Demerdash FM. A Review on oxidative stress and role of antioxidants in diabetes mellitus. Austin Endocrinol Diabetes Case Rep. 2016;1(1):id1006. 
Johansen JS, Harris AK, Rychly DJ, Ergul A. Oxidative stress and the use of antioxidants in diabetes: Linking basic science to clinical practice. Cardiovasc Diabetol. 2005;4(5):1-11.

Kamalakkannan N, Stanely P, Prince M. Antihyperglycaemic and antioxidant effect of rutin, a polyphenolic flavonoid, in streptozotocin-1nduced diabetic Wistar rats. Basic Clin Pharmacol Toxicol. 2006;98(1):97-103.

Karakoca K, Asan-Ozusaglam M, Cakmak YS, Teksen M. Phenolic compounds, biological and antioxidant activities of Onobrychis armena Boiss. \& huet flower and root extracts. Chiang Mai J Sci. 2015;42(2):376-92.

Karamian R, Asadbegy M. Antioxidant activity, total phenolic and flavonoid contents of three onobrychis species from Iran. Pharm Sci. 2016;22(2):112-9.

Koupai-Abyazani MR, Muir AD, Bohm BA, Towers GHN, Gruber MY. The proanthocyanidin polymers in some species of Onobrychis. Phytochemistry. 1993;34(1):113-7.

Kumar S, Kumar D, Deshmukh RR, Lokhande PD, More SN, Rangari VD. Antidiabetic potential of Phyllanthus reticulatus in alloxan-induced diabetic mice. Fitoterapia. 2008;79(1):21-3.

Lu Y, Sun Y, Foo LY, Mcnabb WC, Molan AL. Phenolic glycosides of forage legume Onobrychis viciifolia. Phytochemistry. 2000;55(1):67-75.

Matough FA, Budin SB, Hamid ZA, Alwahaibi N, Mohamed $\mathrm{J}$. The role of oxidative stress and antioxidants in diabetic complications. SQU Med J. 2012;12(1):5-18.

Niture NT, Ansari AA, Naik SR. Anti-hyperglycemic activity of Rutin in streptozotocin-induced diabetic rats: An effect mediated through cytokines, antioxidants and lipid biomarkers. Indian J Exp Biol. 2014;52(7):720-7.
Ozbek H, Bahadir O, Keskin I, Kirmizi NI, Ozbilgin S, Ergene Oz $\mathrm{B}$, et al. Evaluation of hepatoprotective and antidiabetic activity of Alchemilla mollis. Biomed Pharmacother. 2017;86:172-6.

Regos I, Urbanella A, Treutter D. Identification and quantification of phenolic compounds from the forage legume sainfoin (Onobrychis viciifolia). J Agric Food Chem. 2009;57(13):584352.

Rohilla A, Ali S. Alloxan induced diabetes: mechanisms and effects. Int J Research Pharm Biomed Sci. 2012;3(2):819-23.

Tripathi V, Verma J. Different models used to induced diabetes: a comprehensive review. Int J Pharm Pharm Sci. 2014;6(6):29-32.

Usta C, Yildirim AB, Turker AU. Antibacterial and antitumour activities of some plants grown in Turkey. Biotechnol Biotechnol Equip 2014;28(2):306-15.

Veitch NC, Regos I, Kite GC, Treutter D. Phytochemistry Acylated flavonol glycosides from the forage legume, Onobrychis viciifolia (sainfoin). Phytochemistry. 2011;72(45):423-9.

Vinayagam R, Xu B. Antidiabetic properties of dietary flavonoids: a cellular mechanism review. Nutr Metab. 2015;12(60):1-20.

Zengin G, Guler GO, Aktumsek A, Ceylan R, Marie C, Picot N, et al. Enzyme inhibitory properties, antioxidant activities, and phytochemical profile of three medicinal plants from Turkey. Adv Pharmacol Sci. 2015;2015:410675.

Received for publication on $15^{\text {th }}$ March 2018 Accepted for publication on $27^{\text {th }}$ April 2018 